\title{
Knowledge, Attitude and Practice of Mothers on Prevention and Control of Intestinal Parasitic Infection in Sekota Town, Wag-Himra Zone, Ethiopia
}

Mesfin Wudu Kassaw ( $\nabla$ mesfine12a@gmail.com )

Woldia University https://orcid.org/0000-0002-6327-7723

Ayele Mamo Abebe

Debre Birhan Health Science College

Biruk Beletew Abate

Woldia University

Alemu Birara Zemariam

Woldia University

Ayelign Mengesha Kassie

Woldia University

Research article

Keywords: Knowledge, Attitude, Practice, Parasites, Mothers, Children, Sekota, Ethiopia

Posted Date: March 2nd, 2020

DOl: https://doi.org/10.21203/rs.3.rs-15688/v1

License: (9) This work is licensed under a Creative Commons Attribution 4.0 International License.

Read Full License 


\section{Abstract}

Background: Intestinal parasites were a major public health problem in many developing countries. It accounts for 1.5 billion infections with one or more causative agents. The national prevalence of helminthiasis in Ethiopia was $29.8 \%$ with considerable variability across the different regions. Young children had a high infection rate and suffered with a substantial worm burden of A. lumbricoides, trichuris trichiura and schistosomes. Parasitic infection has also serious consequences on human health, such as hepatomegaly, bleeding, esophageal varices, delay in physical development. It also decreases the immunity system, level of intelligence, and labor productivity. Therefore, this study was intended to assess mothers' knowledge, attitude and practice on prevention and control of intestinal parasitic infection among their preschool children in Sekota town, Waghimra zone, Ethiopia

Methods: A cross sectional study was carried out on 378 mothers who had under six years but over two years old children. Although, 384 mothers were selected using sample size calculation in the year 2019, the data was collected from 378 mother-child pairs. A face to face interview was performed using pretested and structured questionnaire in the urban villages, Sekota town. The level of maternal knowledge, attitude and practice were presented in percentage, frequence and table. In each step standard operational procedures were followed.

Results: The overall level of good knowledge or knoledgable, positive attitude and good practice of mothers towards intestinal parasites prevention and control in considering their preschool children in Sekota town was $45.2 \%, 55.3 \%$ and $51.1 \%$ respectively. Seventy-seven $77(20.4 \%)$ respondents reported that they knew Ascaris Lumbricoids , $62(16.4 \%)$ participants wash vegetables as a means of intestinal prevention, and $252(66.7 \%)$ of participants stated that their children had at least one stool examination previously.

Conclusions: The overall level of optimum knowledge, attitude and practice of mothers on prevention and control of intestinal parasites is low. In particular, the level of optimal knowledge is very low in this study. According to the median parameter, $50 \%$ and above of mothers had both positive attitude and good practice. But mothers who were knowledgeable placed below $50 \%$. Therefore, community awareness about parasitic infestation would be created.

\section{Introduction}

An intestinal parasitic infection (IP) is one of the most common communicable diseases across the world (1). The commonest intestinal parasites are Giardia intestinalis, Entamoeba histolytica, Cyclosporacayetanenensis, and Cryptosporidium species. The infection caused by these parasites are known as giardiasis, amoebiasis, cyclosporiasis, and cryptosporidiosis respectively, and they all parasites associated with diarrhea (2). Globally, more than 1.5 billion individuals infected with one or more intestinal parasitic agents. Of these 1.5 billion victim individuals, 700 and 807 million people were infected by Hookworm and Ascariasis respectively (3). Moreover, intestinal parasites have public health 
importance in developing countries and to the most in sub-Saharan Africa $(3,4)$. These parasitic infections are the leading causes of morbidity and mortality in developing countries (4-6). For example, the prevalence of IP in Nigeria was $67.1 \%$ (5), 47.1\% in western Tajikistan (7), 26.74\% in Bangalore (8), and $49.5 \%$ in Anambra state (9). Similar to other developing countries, the prevalence of helminthiases in Ethiopia high, and had considerable variability across the different administrative regional states. It vary from $27.2 \%$ (10), $47.1 \%$ (11), 53.5\% (11), 77.9\% (12), 83.8\%(13), 84.3\% (14), and 85.1\% (15). Besides such variability, a study conducted in Motta town which is in nearby to this study setting reported that children from low educated mothers were had high odds of intestinal parasitic infection (16). The evidence got from Motta town had supported by other studies that reported low maternal education, and lack of health education about intestinal parasite was associated with a high prevalence of intestinal parasitic infection $(5,9,12,17,18)$. In addition to these mentioned factors, young children are the vulnerable group for IP infection, and the highest infestation rate was reported to occur in this age group. Thus children suffer from substantial burden of Ascaris lumbricoides, Trichuristrichiura, and Schistosomes (19). Children who are infected by parasitic infectious agents are risky to have retarded growth through impaired nutrient utilization $(20,21)$. If the infection left untreated, it would have other serious consequences such as hepatomegaly, splenomegaly, low immunity system, decrease level of intelligence, and esophageal varices $(22,23)$. The nature of helminthiases prevention programs like regular anti-helminthic treatment, improved water supply, sanitation, and health education provoked authors to address maternal KAP (24).

Of the prevention programs, regular mass administration of anthelmintic drugs usually takes place outside the health care settings has been strongly supported by the (WHO). Millions of school-aged children have received anti-helminthic treatment (25-27). However, the control measures have limitations to be fully effective in developing countries due to lack of clean water, poor sanitation, and low coverage of education (28). Since poor sanitation, unsafe drinking water, and lack of toilet facilities are the main factors to the high prevalence of intestinal parasites in tropical and sub-tropical countries (29).

The assumption of healthiness in a single community influenced by four factors. Knowledge, attitude, and practice are the three dominant and significant factors on the dynamicity of society's level of wellbeingness (30). The additional factor for community healthiness is parental characteristics such as level of education, and income (31-33). According to these commencements, mothers' characteristics, knowledge, attitude, and practice towards a certain kind of illness play a major role in either the occurrence or disappearance of a particular disease. Thus, the knowledge, attitude, and practice of mothers play significant role to control or disseminate IP infections. According to the European Commission report a greater knowledge of the environmental factors and WASH indicators that influence soil-transmitted helminthiasis are issues where further research is required. The report indicated that understanding which WASH improvements are required to stop disease transmission, assessing the impact of WASH services on disease morbidity, analyzing how health education can benefit in disease control; and understanding the environmental factors which affect the control of parasites are very important and need to be studied (34). A study from Egypt also showed that mothers with good knowledge presented a lower prevalence of IP infection (35). There is a research that indicated the 
majority of the mothers lacked adequate knowledge about prevention and control methods of helminthic infections abroad (36). One research from Ethiopia was also hypothesized that the highest prevalence of IP might be because of the low level of knowledge, attitude and practice towards intestinal parasitic infection (37). In which the lack of knowledge about the mode of transmission of parasitic infections increases the risk of infections (38).

Hence, a better understanding of the major factors, as well as how social, cultural, behavioral, and community awareness affect the epidemiology and control of intestinal parasites may help to design effective control strategies. Despite the reductions in the prevalence of IP and morbidity have been achieved through chemotherapy, it is accepted that improvements in domestic water supplies, environmental sanitation, health education, access to health services for diagnosis and treatment must be integrated into control and elimination programmers' to assure their effectiveness (39). Thus, periodic deworming certainly can attain a stable reduction in transmission if deworming continues indefinitely. Health education can be provided simply and economically, and its benefit goes beyond the control of helminths infections (40). For health education activities to be effective they will also need the identification of the target audience and the formulation of clear messages, which take into account local knowledge, and attitudes to bring about behavior change (41). Furthermore, the role played by the target population is of great importance. If the members of the community are aware of the negative effects of intestinal helminths on the health of their children, they will be more likely to support and sustain the uptake of MDA intervention measures. From a study in the coastal region of Kenya, there was evidence that more education and knowledge to the community members improved the uptake of MDA (42). In Ethiopia, the main strategies are mass drug administration, and case detection and transmission control. In general, there are relatively sufficient pieces of literature on the prevalence of IP on children but only a few studies have been conducted on KAP about intestinal parasitic infestations control and prevention methods. More importantly, there is no data about KAP on intestinal parasitic infestations control and prevention methods in this study town, Sekota town.

Therefore, this study was intended to assess mothers' knowledge, attitude, and practice about intestinal infestations control and prevention among their preschool children in Sekota town, Ethiopia. The finding of the result will be used to design a health education program that can be further implemented based on the level of maternal knowledge, attitude, and practice. Because a program will be designed to reduce morbidity from soil-transmitted helminthic infections to such levels that these infections are no longer of public-health burden based on the result of maternal KAP. Further, the program will be developed to improve the developmental, functional, and intellectual capacity of the victim children as per the principle of targeted chemotherapy (43). Because, this day there are highly-effective, safe single-dose drugs, such as albendazole, which can be dispensed through healthcare services, school health programs, and community interventions directed at vulnerable groups (4).

\section{Methods}


The study was a community-based descriptive cross-sectional study, and carried out on mothers of Sekota town, which is located in the Amhara regional state, Ethiopia. The town, Sekota is the capital city of Waghimra administrative zone. It far $50 \mathrm{~km}$ from the rock church, Lalibella, and $655 \mathrm{~km}$ from Addis Ababa, the capital city of Ethiopia. The data collection period was from February 15 to March 10/2019. The Sekota town is known for water shortage. The water shortage might be a factor for poor hygiene and sanitation practices. The town, Sekota has two urban kebeles, and both kebeles were included in this study (44).

\section{Sampling and study population}

\section{Sample size determination and sampling procedure}

The sample size used in this study was 384 mothers that determined using single population proportion formula. The mothers were had children aged from 24 months to 59 completed months. Although, the population proportion formula used for calculation was in considering previous unpublished gray litrature $(P, 52.3 \%)(45)$, the power of the sample size was greater than $85 \%$. In calculating the sample size, $10 \%$ none response rate, $95 \% \mathrm{Cl}$, and a $5 \%$ margin of error was taken into account. Simple random sampling technique with proportional allocation was used to get all the 384 mothers. This study's data was collected from mothers while a study entitled Prevalence and risk factors of intestinal parasitic infestations among preschool children in Sekota town, Waghimra zone, Ethiopia conducted. The source paper is published at BMC pediatrics and available at https://bmcpediatr.biomedcentral.com/articles/10.1186/s12887-019-1774-2. Thus, the sample size calculation was similar for the above prevalence study and this current KAP study.

\section{Data collection tools}

A pretested and structured interview-based questionnaire were developed in the English and then translated to Amharic, and re-translated to English version to record and analyze the demographic data, and data related to knowledge, attitude and practice of mothers by two independent translators. The discrepancy between the two translators was corrected in discussion between the translators and authors of this paper. This back and forth translation was rechecked by research experts and senior researchers to keep the consistency of the questionnaire. All the questions were developed in considering prevention and control methods of intestinal parasitic infestations.

\section{Assessment of maternal knowledge, attitude, and practice}

In assessing the KAP of mothers, a validated questionnaires were used. The questionnaires had three sections. The first section was about mother's knowledge. The knowledge questionnaires were 5 and have multiple alternatives to be selected by mothers. Thus, mothers were expected to select at least one correct answer to be knowledgable for that question. The second and third section of the questionnaire was about mother's attitude, and their practice in preventing and controlling IP infection on their under five years old children. The attitude questioners were 7 , and that of the practice questionnaires were 11 . In 
all of these sections, mothers were asked about types of intestinal parasites, mode of transmissions, sign and symptoms of intestinal parasitic infections, methods of prevention and control, and complications of IP. All mothers were interviewed in their local language using closed-ended questions. The data collectors selected from the study area and collected the data under the supervision of the researchers.

Inclusion criteria: mothers with their children, whose age was between 2 and 6 years and lives in Sekota town for at least 6 months were included.

Exclusion criteria: Mother-child pairs who were not lived in Sekota town for 6 months, and mothers who had serious illness were excluded.

\section{Data analysis}

The data were entered into epi-data version 4.2.0.0 and transferred to SPSS version 23 software for analysis. Frequency and percentiles were used to summarize the descriptive statistics of the data. The level of maternal knowledge, attitude and practice were reported as a percentage and presented in tables and graphs. A bivariate correlation was undertaken to assess the relation of total knowledge, attitude, and practice scores. The knowledge questions' scoring methods were performed as per the Guttmann Scale. While entering and analyzing the data of knowledge, unfavorable options got 1 point if mothers don't know the correct answers, and 0 points were assigned for correct answers according to Guttmann scale grading scheme. Those five questions have multiple options. From these multiple options, 1 is for the option "I don't know" and 0 is for all other lists of options. Participants who list one and above correct answers among the given alternatives got 0 points. Therefore, the highest and lowest score is 5 and 0 points. The data of attitude was acquired using a questionnaire containing 7 questions where the point was worth 4 if it was "Extremely disagree", 3 points if it was "Disagree", 2 points if it was "Extremely agree", and 1 point if it was "Agree" (Likert Scale). Thus, the highest score would be 28 points and the lowest score would be 7 points. A group of positive and negative attitude was categorized based on the median value. The data of practice was got using 11 "yes" and "no" ordinary questionnaires where the highest and lowest scores were 11 and 0 points (Ordinal Scale) respectively. The data was recorded as 0 when the respondent's answer was no, and 1 if otherwise.

\section{Data quality}

For every step of data collection, analysis, and management standard operational procedures (SOP) were followed. The questionnaire was pretested on $5 \%$ (20 mothers) of the sample in Woldia town, Amhara region, Ethiopia. The questionnaires used to generate data on the socio-demographic data, knowledge, attitude, and practice were validated before the data collection period. The data was checked for its completeness every evening of the data collection day by all investigators and data collectors. The data collectors were taking one-day refreshment training.

\section{Definitions}


Preschool children: Children whose age was between their first day of year 2, and completed 5 years but not attending their 6 years of birthday.

Intestinal parasites: A microorganism that can infect gastrointestinal tracts of the human body.

Attitude: Mothers' opinion or thought about intestinal parasitic infection, its sign, and symptoms, prevention, and control methods, complication, and other related factors

Positive attitude: Mothers who responded below the median value for attitude questions, in which the median value was 15 in this study

Negative attitude: Mothers who responded above the median value for attitude questions, in which the median value was 15 in this study

Knowledge: Assessment of what mothers described intestinal parasitic infections, its prevention and control methods, complications, and other related factors.

Knowledgeable/good knowledge: Mothers who scored below the median value for knowledge questions, in which the median value was 2 in this study

None knowledgeable/poor knowledge: Mothers who scored above the median value for knowledge questions, in which the median value was 2 in this study

Practice: Assessment of mother's actual activities to prevent and control intestinal parasitic infections in their home and out of home.

Good Practice: Mothers who scored above the median value for practice questions, in which the median value was 14 in this study

Poor Practice: Mothers who scored below the median value for practice questions, in which the median value was 14 in this study

Kebele: The smallest administrative unit of Ethiopia. A kebele is expected to consists of at least five hundred families, or the equivalent of 3,500 to 4,000 persons.

\section{Results}

\section{Maternal socio-demographic status}

Among the 384 mothers, 378(98.4\%) mothers were involved in this study. Of the respondents, 374(98.9\%) participants were Amhara in ethnicity, 317(83.9\%) were a follower of Ethiopian orthodox religion, $157(41.5 \%)$ mothers were unable to read and write, 275(72.8\%) mothers were a housewife and $330(87.3 \%)$ women were married. The majority of the mothers $374(98.9 \%)$ had no both history of abortion and diagnosed diabetic Mellitus during the interview time (Table 1). The mean age of mothers 
was 29.2 with a standard deviation of 5.7. The minimum and maximum age of mothers was 20 and 42 respectively. The maximum and a minimum number of pregnancies among mothers was 8 and 2 respectively The mean age of children involved in the study was 3.15 (Fig. 1).

Table 1

Maternal socio-demographic, behavioral and medical status of the included mothers in Sekota town, Ethiopia, 2018/19 $(n=378)$

\begin{tabular}{|c|c|c|c|c|c|}
\hline \multirow[t]{2}{*}{ Variables } & \multirow[t]{2}{*}{ Categories } & \multicolumn{2}{|c|}{ Parasite infections } & \multirow[t]{2}{*}{ Frequency } & \multirow[t]{2}{*}{ Percent } \\
\hline & & $\begin{array}{l}\text { Negative } \\
\text { No (\%) }\end{array}$ & $\begin{array}{l}\text { Positive } \\
\text { No (\%) }\end{array}$ & & \\
\hline \multirow[t]{2}{*}{ Ethnicity } & Amhara & $265(70.9)$ & $109(29.1)$ & 374 & 98.9 \\
\hline & Tigray & 0 & $4(100)$ & 4 & 1.1 \\
\hline \multirow[t]{4}{*}{ Marital status } & Single & 0 & $4(100)$ & 4 & 1.1 \\
\hline & Divorced & $12(100)$ & 0 & 12 & 3.2 \\
\hline & Married & $233(70.6)$ & $97(29.4)$ & 330 & 87.3 \\
\hline & Widowed & $20(62.5)$ & $12(37.5)$ & 32 & 8.5 \\
\hline \multirow[t]{2}{*}{ Religion } & Orthodox & 228 (71.9) & $89(28.1)$ & 317 & 83.9 \\
\hline & Muslim & $37(60.7)$ & $24(39.3)$ & 61 & 16.1 \\
\hline \multirow[t]{5}{*}{ Education } & Unable to read and write & $97(61.8)$ & $60(38.2)$ & 157 & 41.5 \\
\hline & Read and write & $35(92.1)$ & $3(7.9)$ & 38 & 10.1 \\
\hline & Primary & $63(76.8)$ & $19(23.2)$ & 82 & 21.7 \\
\hline & Secondary & $32(80.0)$ & $8(20.0)$ & 40 & 10.6 \\
\hline & Above secondary & $38(62.3)$ & $23(37.7)$ & 61 & 16.1 \\
\hline \multirow[t]{4}{*}{ Occupation } & Housewife & $188(68.4)$ & $87(31.6)$ & 275 & 72.8 \\
\hline & Government employee & $34(69.4)$ & $15(30.6)$ & 49 & 13.0 \\
\hline & Private employee & $7(63.6)$ & $4(36.4)$ & 11 & 2.9 \\
\hline & Merchant & $36(83.7)$ & $7(16.3)$ & 43 & 11.4 \\
\hline \multirow[t]{2}{*}{ History of abortion } & Yes & $4(100)$ & 0 & 4 & 1.1 \\
\hline & No & $261(69.8)$ & $113(30.2)$ & 374 & 98.9 \\
\hline \multirow[t]{2}{*}{ History of diabetes } & Yes & $4(100)$ & 0 & 4 & 1.1 \\
\hline & No & $261(69.8)$ & $113(30.2)$ & 374 & 98.9 \\
\hline
\end{tabular}




\section{Maternal Knowledge, Attitude And Practice}

The knowledge, attitude, and practice of mothers on prevention and control of intestinal parasitic infection among their pre-school children in Sekota town were determined using the median value of total knowledge, attitude, and practice scores. The mean and median value of maternal knowledge was 2.57 , and 2.00 respectively. The mean and median value of maternal attitude was 16.03 , and 15.00 respectively. Whereas the mean and the median value of maternal practice was 14.77 , and 14.00 respectively (Table 2 ).

Table 2

The central statistics and variance used to categorize the knowledge, attitude, and practice of mothers in Sekota town, Amhara, Ethiopia, 2019

\begin{tabular}{|llll|}
\hline Descriptive statistics & Sum of knowledge & Sum of attitude & Sum of practice \\
\hline Mean & 2.57 & 16.03 & 14.77 \\
\hline Standard deviation & 4.20 & 1.545 & 2.48 \\
\hline Median & 2.00 & 15.00 & 14.00 \\
\hline Below the mean (\%) & 45.2 & 62.7 & 48.9 \\
\hline Below the median (\% \& 95\% Cl) & $45.2(40.2,50.5)$ & $55.3(50.8,61.1)$ & $48.9(43.9,54.0)$ \\
\hline Above the mean (\%) & 54.8 & 37.3 & 51.1 \\
\hline Above the median (\% \& 95\% Cl) & $54.8(49.5,59.8)$ & $44.7(38.9,49.2)$ & $51.1(46.0,56.1)$ \\
\hline
\end{tabular}

\section{Maternal knowledge}

In this study, 207 (54.8\%) of the women were none knowledgeable, whereas 171 (45.2\%) of mothers were knowledgeable about intestinal parasitic Infection prevention and control methods for preschool children.

\section{Knowledge About Intestinal Parasites}

Majority of the mothers, 77 (20.4\%) reported that they knew Ascaris lumbricoides, 41 (10.8\%) knew E. histolytic, and 52(13.8\%) knew Giardia lamblia (Table 3). 
Table 3

Maternal knowledge about intestinal parasitic infestations prevention and control methods in Sekota town, Ethiopia, 2018/19 $(n=378)$

\begin{tabular}{|c|c|c|c|c|}
\hline No & Variables & Categories & Frequency & Percent \\
\hline \multirow[t]{8}{*}{1} & \multirow{8}{*}{$\begin{array}{l}\text { Which intestinal parasite you } \\
\text { know }(n=378)\end{array}$} & Ascaris Lumbricoids & 77 & 20.4 \\
\hline & & E. Histolytica/dispar & 41 & 10.8 \\
\hline & & G. Lambila & 52 & 13.8 \\
\hline & & Hookworm & 17 & 4.5 \\
\hline & & $\begin{array}{l}\text { G. Lambila and E. } \\
\text { Histolytica/dispar }\end{array}$ & 23 & 6. \\
\hline & & $\begin{array}{l}\text { Hookworm and E. } \\
\text { Histolytica/dispar }\end{array}$ & 9 & 2.4 \\
\hline & & $\begin{array}{l}\text { Ascaris Lumbricoids and G. } \\
\text { Lambila }\end{array}$ & 32 & 8.5 \\
\hline & & I don't know & 127 & 33.6 \\
\hline \multirow[t]{7}{*}{2} & \multirow{7}{*}{$\begin{array}{l}\text { Which prevention mechanisms } \\
\text { you know }(n=378)\end{array}$} & Hand washing & 42 & 11.1 \\
\hline & & Using latrine & 30 & 8 \\
\hline & & washing vegetables & 62 & 16.4 \\
\hline & & $\begin{array}{l}\text { Avoid food and water } \\
\text { contamination }\end{array}$ & 6 & 1.6 \\
\hline & & Hand washing and Using latrine & 29 & 7.7 \\
\hline & & $\begin{array}{l}\text { washing vegetables and Using } \\
\text { latrine }\end{array}$ & 18 & 4.8 \\
\hline & & I don't know & 187 & 49.5 \\
\hline \multirow[t]{6}{*}{3} & \multirow{6}{*}{$\begin{array}{l}\text { Which mode of transmission } \\
\text { you know }(n=378)\end{array}$} & soil contact & 75 & 19.9 \\
\hline & & contaminated water & 29 & 7.7 \\
\hline & & contaminated food & 65 & 17.2 \\
\hline & & $\begin{array}{l}\text { Uncooked vegetables and unclean } \\
\text { fruits }\end{array}$ & 17 & 4.5 \\
\hline & & $\begin{array}{l}\text { contaminated food and } \\
\text { contaminated water }\end{array}$ & 9 & 2.4 \\
\hline & & $\begin{array}{l}\text { Contaminated food and soil } \\
\text { contact }\end{array}$ & 20 & 5.3 \\
\hline
\end{tabular}




\begin{tabular}{|c|c|c|c|c|}
\hline No & Variables & Categories & Frequency & Percent \\
\hline & & $\begin{array}{l}\text { Uncooked / unclean vegetables and } \\
\text { fruits and soil contact }\end{array}$ & 15 & 3.9 \\
\hline & & I do not know & 148 & 39.1 \\
\hline \multirow[t]{7}{*}{4} & \multirow{7}{*}{$\begin{array}{l}\text { Which sign and symptoms of } \\
\text { IP you know }(n=378)\end{array}$} & Diarrhea & 66 & 17.5 \\
\hline & & Abdominal cramp & 38 & 10 \\
\hline & & Vomiting & 19 & 5 \\
\hline & & Anorexia & 9 & 2.4 \\
\hline & & Diarrhea and Vomiting & 24 & 6.4 \\
\hline & & Abdominal cramp and Diarrhea & 17 & 4.5 \\
\hline & & I do not know & 205 & 54.2 \\
\hline \multirow[t]{6}{*}{5} & \multirow{6}{*}{$\begin{array}{l}\text { Which complication you know } \\
(\mathrm{n}=378)\end{array}$} & Malnutrition & 58 & 15.4 \\
\hline & & Anemia & 12 & 3.2 \\
\hline & & Growth retardation & 20 & 5.3 \\
\hline & & Malnutrition and Growth retardation & 32 & 8.4 \\
\hline & & Growth retardation and Anemia & 7 & 1.9 \\
\hline & & I do not know & 249 & 65.8 \\
\hline
\end{tabular}

\section{Knowledge About Prevention And Control Of Intestinal Parasites}

From 378 mothers, $62(16.4 \%)$ respondents mentioned washing vegetables, $42(11.1 \%)$ respondents consider hand washing, $30(8 \%)$ raised latrine utilization as prevention and control methods of IP infections (Table 3).

\section{Knowledge About The Mode Of Transmission Of Intestinal Parasites}

Among the total respondents, 75(19.9\%) considered soil contact, $29(7.7 \%)$ mentioned contaminated water, and $65(17.2 \%)$ describe contaminated food as a mode of transmission (Table 3).

\section{Knowledge About Sign And Symptoms Of Intestinal Parasites}

Of the total 378 mothers, 66 (17.5\%) listed diarrhea, 38 (10\%) indicated abdominal cramp, and $19(5 \%)$ mentioned vomiting as the sign and symptoms of intestinal parasitic infections (Table 3 ). 
Regarding the complication of intestinal parasitic infection, malnutrition was considered by 58 (15.4\%) respondents, growth retardation by 20 (5.3\%) mothers and 32(8.4\%) mothers were considered both malnutrition and growth retardation is complication of parasitic infestations (Table 3 )

\section{Attitude}

In this study, 169 (44.7\%) mothers had negative attitude, and 209 (55.3\%) mothers had a positive attitude about intestinal parasitic infections prevention and control methods on their preschool children (Table 4). 
Table 4

Maternal attitude about intestinal parasitic infestations prevention and control method in Sekota town, Ethiopia, 2018/19 $(n=378)$

\begin{tabular}{|c|c|c|c|c|}
\hline S.no & Variable & Categories & Frequency & Percent \\
\hline \multirow[t]{5}{*}{1} & \multirow[t]{5}{*}{$\begin{array}{l}\text { Lack of hygiene is the cause of intestinal parasitic } \\
\text { infections }\end{array}$} & $\begin{array}{l}\text { Extremely } \\
\text { Agree }\end{array}$ & 101 & 26.7 \\
\hline & & Agree & 164 & 43.4 \\
\hline & & Neutral & 44 & 11.6 \\
\hline & & Disagree & 51 & 13.5 \\
\hline & & $\begin{array}{l}\text { Extremely } \\
\text { Disagree }\end{array}$ & 18 & 4.8 \\
\hline \multirow[t]{5}{*}{2} & \multirow[t]{5}{*}{ Intestinal parasites can be prevented and treated } & $\begin{array}{l}\text { Extremely } \\
\text { Agree }\end{array}$ & 135 & 35.7 \\
\hline & & Agree & 168 & 44.4 \\
\hline & & Neutral & 24 & 6.3 \\
\hline & & Disagree & 25 & 6.6 \\
\hline & & $\begin{array}{l}\text { Extremely } \\
\text { Disagree }\end{array}$ & 26 & 6.9 \\
\hline \multirow[t]{5}{*}{3} & \multirow[t]{5}{*}{$\begin{array}{l}\text { Health education can reduce the prevalence of } \\
\text { intestinal parasitic infections }\end{array}$} & $\begin{array}{l}\text { Extremely } \\
\text { Agree }\end{array}$ & 108 & 28.6 \\
\hline & & Agree & 173 & 45.8 \\
\hline & & Neutral & 37 & 9.8 \\
\hline & & Disagree & 34 & 9.0 \\
\hline & & $\begin{array}{l}\text { Extremely } \\
\text { Disagree }\end{array}$ & 26 & 6.9 \\
\hline \multirow[t]{5}{*}{4} & \multirow[t]{5}{*}{$\begin{array}{l}\text { One of the complications of intestinal parasite is } \\
\text { growth retardation }\end{array}$} & $\begin{array}{l}\text { Extremely } \\
\text { Agree }\end{array}$ & 93 & 24.6 \\
\hline & & Agree & 202 & 53.4 \\
\hline & & Neutral & 36 & 9.5 \\
\hline & & Disagree & 34 & 9.0 \\
\hline & & $\begin{array}{l}\text { Extremely } \\
\text { Disagree }\end{array}$ & 13 & 3.4 \\
\hline 5 & $\begin{array}{l}\text { Uses of soap while washing hand or face can } \\
\text { prevent intestinal parasitic infections }\end{array}$ & $\begin{array}{l}\text { Extremely } \\
\text { Agree }\end{array}$ & 104 & 27.5 \\
\hline
\end{tabular}




\begin{tabular}{|c|c|c|c|c|}
\hline S.no & Variable & Categories & Frequency & Percent \\
\hline & & Agree & 173 & 45.8 \\
\hline & & Neutral & 24 & 6.3 \\
\hline & & Disagree & 38 & 10.1 \\
\hline & & $\begin{array}{l}\text { Extremely } \\
\text { Disagree }\end{array}$ & 39 & 10.3 \\
\hline \multirow[t]{5}{*}{6} & $\begin{array}{l}\text { Raw food consumption is the cause of worm } \\
\text { infestation }\end{array}$ & $\begin{array}{l}\text { Extremely } \\
\text { Agree }\end{array}$ & 75 & 19.8 \\
\hline & & Agree & 171 & 45.2 \\
\hline & & Neutral & 63 & 16.7 \\
\hline & & Disagree & 42 & 11.1 \\
\hline & & $\begin{array}{l}\text { Extremely } \\
\text { Disagree }\end{array}$ & 27 & 7.1 \\
\hline \multirow[t]{5}{*}{7} & $\begin{array}{l}\text { Foods prepared in outdoor are risks for intestinal } \\
\text { parasitic infections }\end{array}$ & $\begin{array}{l}\text { Extremely } \\
\text { Agree }\end{array}$ & 66 & 17.5 \\
\hline & & Agree & 145 & 38.4 \\
\hline & & Neutral & 60 & 15.9 \\
\hline & & Disagree & 56 & 14.8 \\
\hline & & $\begin{array}{l}\text { Extremely } \\
\text { Disagree }\end{array}$ & 51 & 13.5 \\
\hline
\end{tabular}

\section{Practice}

Among the 378 mothers, 193(51.1\%) mothers were had good practice, and 185(48.9\%) of mothers were had poor practice about intestinal parasitic infections prevention and control methods on their preschool children (Table 5). 
Table 5

Maternal practices about intestinal parasitic infestations prevention and control mechanisms in Sekota town, Ethiopia, 2018/19( $\mathrm{n}=378)$

\begin{tabular}{|c|c|c|c|}
\hline Variables & Categories & Frequency & Percent \\
\hline \multirow[t]{2}{*}{ Did your child had any stool examination history previously? } & Yes & 252 & 66.7 \\
\hline & No & 126 & 33.3 \\
\hline \multirow[t]{2}{*}{ Do you wash your child hand before any meal time? } & Yes & 295 & 78.0 \\
\hline & No & 83 & 22.0 \\
\hline \multirow[t]{2}{*}{ Do you wash your child hand after any meal time? } & Yes & 286 & 75.7 \\
\hline & No & 92 & 24.3 \\
\hline \multirow[t]{2}{*}{ Do you shorten your child nails? } & Yes & 248 & 65.6 \\
\hline & No & 130 & 34.4 \\
\hline \multirow{2}{*}{$\begin{array}{l}\text { Did you give drug for your child for prevention of intestinal } \\
\text { parasite? }\end{array}$} & Yes & 197 & 52.1 \\
\hline & No & 181 & 47.9 \\
\hline \multirow{2}{*}{$\begin{array}{l}\text { Do you use chemically treated/tap water to prevent intestinal } \\
\text { parasitic infection? }\end{array}$} & Yes & 278 & 73.5 \\
\hline & No & 100 & 26.5 \\
\hline \multirow[t]{2}{*}{ Do you wash your child hand after defecation? } & Yes & 243 & 64.3 \\
\hline & No & 135 & 35.7 \\
\hline \multirow{2}{*}{$\begin{array}{l}\text { Had your child ever been diagnosed for intestinal parasitic } \\
\text { infection }\end{array}$} & Yes & 94 & 24.9 \\
\hline & No & 284 & 75.1 \\
\hline \multirow[t]{2}{*}{ Do use soap to clean utensils } & Yes & 243 & 64.3 \\
\hline & No & 135 & 35.7 \\
\hline \multirow[t]{2}{*}{ Did you wash before cooking meal } & Yes & 327 & 86.5 \\
\hline & No & 51 & 13.5 \\
\hline \multirow{2}{*}{$\begin{array}{l}\text { Do you wash fruits and raw vegetables thoroughly before } \\
\text { eating }\end{array}$} & Yes & 269 & 71.2 \\
\hline & No & 109 & 28.8 \\
\hline
\end{tabular}

\section{Correlation Of Knowledge, Attitude, And Practice}

The KAP questions were sum up together to determine the level of knowledge, attitude, and practice. The total score of knowledge and attitude or practice, as well as a total score of attitude and practice, were run in the covariate model. The model was selected to determine whether the KAP of mothers had a 
correlation or not. The number of family and number of pregnancy were inversely correlated with the total score of attitude. Whereas the number of families, number of live birth, and number of pregnancies were had a direct correlation with the total score of practice. But the total score of knowledge had no correlation with any of the variables. More importantly, there is no correlation between the total score of knowledge and attitude or practice and total score of attitude and practice (Table 6).

Table 6

the association of total knowledge, attitude, and practice scores with predictor continuous variables

\begin{tabular}{|c|c|c|c|c|c|c|}
\hline \multirow[t]{2}{*}{ Variables } & \multicolumn{2}{|c|}{ Total knowledge } & \multicolumn{2}{|l|}{ Total practice } & \multicolumn{2}{|l|}{ Total attitude } \\
\hline & $\begin{array}{l}\text { Pearson } \\
\text { correlation (r) }\end{array}$ & $\begin{array}{l}\mathrm{P}- \\
\text { value }\end{array}$ & $\begin{array}{l}\text { Pearson } \\
\text { correlation (r) }\end{array}$ & $\begin{array}{l}\mathrm{P}- \\
\text { value }\end{array}$ & $\begin{array}{l}\text { Pearson } \\
\text { correlation (r) }\end{array}$ & $\begin{array}{l}\mathrm{P} \text { - } \\
\text { value }\end{array}$ \\
\hline Maternal age & 0.09 & 0.073 & -0.07 & 0.19 & -0.07 & 0.19 \\
\hline $\begin{array}{l}\text { Number of } \\
\text { family }\end{array}$ & 0.04 & 0.45 & $0.23^{\star \star}$ & 0.00 & $-0.18^{\star \star}$ & -0.00 \\
\hline $\begin{array}{l}\text { Number of live } \\
\text { birth }\end{array}$ & 0.05 & 0.32 & $0.12^{*}$ & 0.021 & 0.05 & 0.32 \\
\hline $\begin{array}{l}\text { Number of } \\
\text { pregnancy }\end{array}$ & 0.05 & 0.32 & $0.11^{*}$ & 0.021 & $-0.21^{\star \star}$ & 0.00 \\
\hline $\begin{array}{l}\text { Total } \\
\text { knowledge }\end{array}$ & - & - & -0.02 & 0.72 & 0.04 & 0.47 \\
\hline Total attitude & & & 0.03 & 0.54 & - & - \\
\hline
\end{tabular}

\section{Discussion}

Intestinal parasitic infections acquired at any age, but young children are more susceptible to disproportionally (19). Though intestinal parasitic infection is a global problem, it is more devastating in developing countries $(3,4)$, particularly Ethiopia, and the study area, Sekota town in which the study area has a water shortage (44). This may contribute to poor hygienic practice, and a low level of maternal practice to prevent IP infection. In addition, assessing the knowledge, attitude, and practice of individuals regarding the risk factors, mode of transmission, and intermediate host in the community have great importance for identifying, designing and implementing effective community-based interventions (46, 47). In this study, the reported level of good maternal knowledge, positive attitude, and good maternal practice in preventing and controlling intestinal parasitic infection on their pre-school children was $45.2 \%$ $(95 \% \mathrm{Cl}, 40.2,50.5), 55.3 \%(95 \% \mathrm{Cl}, 50.8,61.1)$, and $51.1 \%(95 \% \mathrm{Cl}, 46.0,56.1)$ respectively. Whereas $54.8 \%(49.5,59.8), 44.7 \%(38.9,49.2)$, and $48.9 \%(43.9,54.0)$ of respondents were had poor maternal knowledge, negative attitude, and poor maternal practice. In this study, the total level of mothers' knowledge was lower than a study that was done in Tigray, Ethiopia in which $94.4 \%$ of respondents had good knowledge about intestinal parasitoids prevention (48). This discrepancy might be because of the 
different study populations. In our study, only mothers who had under five years old children were considered but the referred paper included both males and females irrespective of the presence of underfive children. The finding of this paper was also lower than a study done in Senbete and Bete towns, north Shoa, Ethiopia that reported $60.3 \%$ of respondents were knowledgeable (45). This variance might be due to the use of different operational definitions of knowledge. Our study used the median value to categorize as knowledgable and none knowledgable but the compared study consider a total score cut off points. In this study, on each knowledge questionnaire, $75(19.9 \%)$ of respondents considered soil contact, and 65 (17.2\%) mothers indicated contaminated food as a mode of IP transmission. This is lower than a study conducted in Egypt that reported $41.8 \%$ of mothers mentioned contaminated food, and $41.7 \%$ state soil as a mode of transmission (35). In this study $62(16.4 \%)$ of mothers stated washing vegetables, and $42(11.1 \%)$ declared hand washing to prevent IP infection. This finding is also significantly lower than the study conducted in Egypt that washing hands and washing vegetables indicated by $73.3 \%$ and $62.2 \%$ of the respondents to prevent IP infections respectively (35). The difference might be because of the socio-economic status difference between Ethiopia, and Egypt. The finding of this study was agreed with a study done in Wondo Genet in some of the knowledge related variables, in which mothers from Wondo Genet responded that drinking river water, chewing sugar cane, feeding uncooked cabbage to children, and green pepper was associated with intestinal parasitic infections (49). In this study, mothers mentioned diarrhea, abdominal cramp, vomiting, and anorexia as the sign and symptoms of intestinal parasitic infections. This finding was also aligned with the study done in Wondo genet (49). In the current study, mothers mentioned malnutrition, anemia, and growth retardation could occur as a complication of intestinal parasites which was similar to a study that mentioned intestinal parasites could cause serious health problems including growth retardation, and malnutrition unless treated (49). This agreement might be because of similar study design, similar study population, and a relatively similar degree of urbanization. In the current study, the overall level of positive attitude was $55.3 \%$, which is similar with a study done in Senbete and Bete towns, Ethiopia that reported $56.1 \%$ of mothers had a positive attitude, and $43.9 \%$ had a negative attitude towards the prevention and control of intestinal parasites (45). The similarity might be due to similar socio-economic status, design, and setting, in which both Sekota, and Senbete and Bete towns are medium scales, and dry towns. In this study, $35.7 \%$ of mothers extremely agree, and $44.4 \%$ of mothers agree on the importance of IP treatment. This is lower than a study from Tigray, Ethiopia in which $300(99.7 \%)$ of the participants were agree with the importance of medication on treating IP infections (48). This discrepancy might be because of different study areas, that might have different health care services including health education, and health extension package coverage.In this study, $44.4 \%$ of mothers agreed that IP infection can be treated, which is lower than the study conducted in Egypt that (93.4\%) of respondents agreed that worms could be treated (35). The difference might be because of the socio-economic status difference between Ethiopia, and Egypt. The overall level of good maternal practice in Sekota town about intestinal parasitic infection prevention and control was $51.1 \%$, which was in line with the study done in Astha block (54\%) (50). The agreement might be due to having similar socio-economic status, and health care service across the study areas. But the current study had higher good maternal practice than a study done in Ichhawar that reported only $2 \%$ of mothers were had a good practice (51). This substantial difference 
might be because of different socio-economic status, health care services, sample size, and study area. In this study, $66.7 \%$ of mothers had a routine stool examination for helminths. This agreed with a study that reported mothers had routine stool examination for helminths among their preschool children (52). The agreement might be due to health care service availability and government commitment to control IP through periodic deworming across the world. In this study, $78.0 \%$ of mothers wash their children's hand before a meal. This finding is lower than a study from Tigray that reported 301(100) respondents wash their hands before meal (48). The disagreement might be due to geographic difference, and availability of water. In the current study, there is considerable water shortage (44) in relative to the reference. On each specific practice questions, $78.0 \%$ of the respondents wash their hands, which is higher than a study that was done in Zimbabwe, in which only 42 (24.4\%) of children washed their hands some times before eating food (53). In this research, $64.3 \%$ of mothers wash their children after using the latrine. This is higher than research that reported $29(16.9 \%)$ of children never washed their hands after using the toilet, and $69(40.1 \%)$ of children washed their hands sometimes after using the toilet (53). The inconsistency might be because of the study population difference. In our study, the practice of mothers was assessed but in the compared study from Zimbabwe collected data from children. In this study $52.1 \%$ of mothers gave deworming for their children. This is lower than a study from Tigray that reported $299(99.3 \%)$ of respondents took deworming (48). The inconsistency might be because of the health education provided. In our study, there are only universal health care services than the compared study area, which had special health education as the area is known for schistosomiasis. On the covariate analysis, all of the total scores of knowledge, attitude, and practice have no correlation. The reason might be the sample size, or the overall low level of maternal knowledge, attitude, and practice which causes to lack of correlation. The low level of knowledge, attitude, and practice might indicate that the study area had no basic and conceptualized awareness about IP. The lack of basic and conceptualized knowledge might be an indication of the absence of a correlation between KAP of mothers. In general, this study tries to indicate the level of knowledge, attitude, and practice of Sekota town's mothers against others' work and other areas level of KAP, although the previous studies were limited on this title and persuade us to have such a restricted discussion.

\section{Conclusion}

The overall level of maternal good knowledge, maternal positive attitude, and maternal good practice on prevention and control of intestinal parasites in Sekota town were significantly low. The level of knowledge was exclusively low in this study. More than half of mothers have a positive attitude and good practice. The total score of knowledge, attitude, and practice had no correlation. This might be because of the small sample size, or designs we used. Therefore, community awareness about intestinal parasitic infection prevention and control should be created through community mobilization like a weekend campaign or structured training for mothers. In addition, further research is needed with a large sample size, and different methods to asses the relation of KAP, and factors associated with KAP.

\section{Limitation Of The Study}


Mainly, it is a descriptive study and the association of knowledge, attitude, and practice were not assessed using logistic regression. Therefore, the impact of knowledge and attitude on practice is not indicated with strong statistical analysis. Even the covariate analysis indicated that the KAP of mothers is not correlated with each other. In addition to this, different factors that may be indicators of knowledge, attitude, and practice are not addressed. This may limit the strength of the conclusion and recommendation forwarded to the community. Yet, some continuous variables were assessed with the KAP of mothers using the covariate model.

\section{Abbreviations}

IP-Intestinal parasites, SOP-standard operational procedures, SPSS-Statistical package for social science, KAP- knowledge, attitude and practice

\section{Declarations}

\section{Ethics approval and consent to participate}

The ethical clearance was obtained from Institutional Review Board of Woldia University (WDU/IRB/0910/2019). A support letter was also obtained from Woldia University, research directorate office. Then after, a subsequent contact was made with the chairmen of the Sekota town administration and each kebeles head offices. A written permission was got from the heads of each kebeles, and Sekota zonal administration. The data collectors get written consent from mothers after explaining the purpos of the study. Mothers anonymity and confidentiality were maintained by allowing opposition and or discontinuation of the interview and omitting the name and personal identification of respondents, because it was not compelled to the study.

\section{Consent for publication}

Participants were informed and gave their written consent to publish the findings in repeatable international journal. The consent for publication was received together with the consent to participate in the study.

\section{Availability of data and materials}

The data that supports the conclusions of this research could be available to researchers or policymakers, and any others who need the data to be used for non-commercial purposes through requesting one of the authors.

\section{Competing interests}

The authors declare that they have no conflicting of interests.

\section{Funding}


This study was supported by Woldia University, college of health science, research and community service office. The funder had not contributed in collecting, analyzing and writing the final version of this paper except full financial support.

\section{Authors' affiliation}

${ }^{1}$ Department of nursing, college of health science, Woldia University, Woldia, Ethiopia, Po Box $400,{ }^{2}$ Department of nursing, college of health science, Debre Berhan University, Debre Berhan, Ethiopia, Po Box 400

\section{Authors' contributions}

Conceived the title and designed the study: MWK, AMA, BBA, ABZ, and AMK. Field study: MWK, ABZ, AMA, and BBA. Analyzed the data: MWK, AMK, and ABZ. Critically revising the work: MWK, and BBA. Writing the final paper: MWK, AMA, ABZ, and BBA. All authors had read and approved the final version of this manuscript with consideration of full accountability.

\section{Acknowledgments}

We would like to acknowledge Woldia University, college of health science, research and community service office for full sponsorship of the research through the annual call for a research grant. We would also like to extend our gratitude to Mr. Solomon Moges, and Getnet Kumie for their active participation in developing the proposal. Finally, we acknowledge the data collectors, and participants, who were directly involved in producing this data set.

\section{References}

1. Hotez PJ. Helminth infections: the great neglected tropical diseases. J Clin Invest. 2008; 118: 13111321. 2, WHO. Intestinal parasite: Burden and trends, 2013. Available at https://apps.who.int/ctd/intpara/burdens.htm.

2. Davis AN, Haque R, Petri WA. Update on protozoan parasites of the intestine. Curr Opin Gastroentrol 2002;18:10-4.

3. World Health Organization. Weekly epidemiological record. Soil-transmitted helminthiases: number of children treated in 2013. 10 (90), 89-96.

4. World Health Organization. Prevention and control of Schistosomiasis and soil-transmitted helminthiasis. Report of the WHO expert committee. Geneva. 2002

5. Auta T., Oricha EK., Audu K. Studies on the Intestinal Helminths Infestation among Primary School Children in Gwagwada, Kaduna, North-Western Nigeria. Journal of Biology, Agriculture, and Healthcare. 2013; 3: 7, Available at iiste.org

6. Haque R. Human intestinal parasites. Journal of Health, Population, and Nutrition. 2007; 25, 387-391 
7. Matthys B. Prevalence and risk factors of helminths and intestinal protozoa infections among children from primary schools in western Tajikistan. Parasites and Vectors. 2011; 4: 195. http://www.parasitesandvectors.com/content/4/1/195

8. Golia S., Sangeetha K.T., Vasudha C.L. Prevalence of parasitic infections among primary school children in Bangalore. International Journal of Basic and Applied Medical Sciences. 2014; Vol. 4: 1, 2277-2103. Available at http://www.cibtech.org/jms.htm

9. Emmy-EGBE., et.al. Prevalence of Intestinal helminths in students of Ihiala local government area of Anambra state. Journal of Applied Technology in Environmental Sanitation, 2012; 2 (1): 23-30

10. Tadesse $G$. The prevalence of intestinal helminthic infections and associated risk factors among school children in Babile town, Eastern Ethiopia. Ethiop. J. Health Dev. 2005; 19 (2): 140-147

11. Debalke S., Worku A., Jahur N., et al. Soil-transmitted helminths and associated factors among school children in Jimma Town, Southwest Ethiopia. Ethiop J Health Sci. 2013; Vol. 23: 3.

12. Alamir M., Awoke W., Feleke A. Intestinal parasites infection and associated factors among Dagi Primary School, Amhara National Regional State, Ethiopia. 2013; 5: 10, 1697-1701

13. Legesse, M. and Erko, B. Prevalence of intestinal parasites among school children in a rural area close to the southeast of Lake Langano, Ethiopia. The Ethiopian Journal of Health Development. $2004 ; 18,116-120$

14. Workneh T, Esmael A, Ayichiluhm M. Prevalence of Intestinal Parasitic Infections and Associated Factors among Debre Elias Primary School Children, East Gojjam Zone, Amhara Region, North West Ethiopia. J Bacteriol Parasitol. 2014 5: 181.

15. Nyantekyi, L.A., Legesse, M., Belay, M., et al. Intestinal parasitic infections among under-five children and maternal awareness about the infections in Shesha Kekele, Wondo Genet, Southern Ethiopia. The Ethiopian Journal of Health Development. 2010; 24, 185-190

16. Mulusew Andualem Asemahagn. "Parasitic Infection and Associated Factors among the Primary School Children in Motta Town, Western Amhara, Ethiopia." American Journal of Public Health Research, vol. 2, no. 6 (2014): 248-254. doi: 10.xza/ajphr-2-6-6.).

17. Abate A., et. al. Cross-Sectional Study on the Prevalence of Intestinal Parasites and Associated Risk Factors in Teda Health Centre, Northwest Ethiopia. ISRN Parasitology, 2013. Available at http://dx.doi.org/10.5402/2013/757451.

18. Abossie A., Seid M. Assessment of the prevalence of intestinal parasitosis and associated risk factors among primary school children in Chencha town, Southern Ethiopia. BMC Public Health. 2014; 14: 166.

19. Albonico $\mathrm{M}$, Allen $\mathrm{H}$, Chitsulo $\mathrm{L}$, et al. Controlling soil-transmitted helminthiasis in pre-school-age children through preventive chemotherapy. PLoS Negl Trop Dis 2008;2:e126.

20. Awasthi S, Bundy DAP, Savioli L. Helminthic Infections. BMJ 2003;19:885-8.

21. Kvalsvig JD, Cooppan RM, Connolly KJ. The effects of parasite infections on cognitive processes in children. Ann Trop Med Parasitol 1991;85:551-68. 
22. Working to overcome the global impact of neglected tropical diseases. First WHO report on neglected tropical diseases. Geneva: WHO; 2010. Available at: http:// whqlibdoc.who.int/publications/2010/9789241564090_eng.pdf.

23. USAID's Neglected Tropical Diseases Program. Soil-transmitted Helminthiasis. 2014, available at :https://www.neglecteddiseases.gov/target_diseases/soil_transmitted helminthiasis/

24. Belayhun Y, Medhin G, Amberbir A. Prevalence andrisk factor for helminthic infestations in Butajera Ethiopia, a population-based study. BMC Public Health. 2010. 10: 21

25. Fenwick A, Webster JP, Bosque-Oliva E. The Schistosomiasis Control Initiative (SCI): rationale, development and implementation from 2002-2008. Para. 2009; 136: 1719-1730.

26. Savioli L, Gabrielli AF, Montresor A, et al. Schistosomiasis control in Africa: 8 years after World Health Assembly Resolution 54.19. Para. 2009; 136: 1677-1681.

27. Utzinger J, Raso G, Brooker S, et al. Schistosomiasis and neglected tropical diseases: towards integrated and sustainable control and a word of caution. Para. 2009; 136: 1859-1874

28. Steinmann P, Keiser J, Bos R, et al. Schistosomiasis and water resources development and estimates of people at risk. Lancet Infect Dis. 2006. 6(7): 411-425.

29. Mahfouz AAR, El-Morshedy H, Farghaly A, et al. Ecological determinants of intestinal parasitic infections among pre-school children in an Urban Squatter Settlement of Egypt. Journal of Tropical Pediatric 1997;43:341-44.).

30. Notoatmodjo S, editor. Promosi kesehatan teori dan aplikasi. Jakarta: Rineka Cipta; 2005.

31. Omoigberale A, Airauhi L. Aspects of the epidemiology of intestinal parasitosis (IP) in children: knowledge, practice and perceptions of mothers. Niger J Clin Pract. 2006;9(2):109-13

32. Ferrer RL, Palmer R, Burge S. The family contribution to health status: a population-level estimate. Ann Fam Med.2005;3(2):102-8.

33. Kattula D, Sarkar R, Ajjampur SSR, et al. Prevalence and risk factors for soil transmitted helminth infestations among school children in South India. Indian J Med Res. 2014;139(1):76- 82.

34. Imperial College, London. School-Based Deworming, A Clear Role for the European Commission, The partnership for child development, October 2014

35. Filippo Curtale, Patrizio Pezzotti, Abdel Latif et al. Knowledge, perceptions and behaviour of mothers toward intestinal helminths in Upper Egypt: Implications for control. Health policy and planning; Oxford University Press 1998 13(4): 423^432

36. Amar Tripura, Taranga Reang, Kaushik Tripura, et al. "A study of knowledge and practice on intestinal helminthiasis among rural tribal mothers of under five children in Mohanpur block, west district of Tripura: a north eastern state of India". Journal of Evolution of Medical and Dental Sciences 2013; Vol2, Issue 47, November 25;

37. Hailegebriel Tamrat. Prevalence of intestinal parasitic infections and associated risk factors among students at Dona Berber primary school, Bahir Dar, Ethiopia. BMC Infectious Diseases, (2017) 17:362 
38. Kloos H. Human behavior, health education and schistosomiasis control: A review. SocSci Med 1995;40:1497-1511.

39. Wynd S, Melrose WD, Durrheim DN, et al. Understanding the community impact of lymphatic filariasis: a review of the socio-cultural literature. Bull World Health Organ. 2007; 85: 493- 498. https://doi.org/10.2471/BLT.06.031047 PMID: 17639248

40. Hotez PJ, Bundy DAP, Beegle K, et al. Helminth infections: soil-transmitted helminth infections and schistosomiasis. In Jamison DT, Breman JG, Measham AR, Alleyne G, Claeson M, editors. Disease control priorities in developing countries, 2nd edn. New York: Oxford University Press. 2006. pp. 46782

41. Uchoa E, Barreto SM, Firmo JO, et al. The control of schistosomiasis in Brazil: an ethnoepidemiological study of the effectiveness of a community mobilization program for health education. Soc Sci Med. 2000; 51: 1529-1541. PMID: 11077955.

42. Okello $\mathrm{G}$, Jones $\mathrm{C}$, Bonareri $\mathrm{M}$, et al. Challenges for consent and community engagement in the conduct of cluster randomized trial among school children in low income settings: experiences from Kenya. BioMed Central. 2013; 14:142].

43. Bundy DA, Wong MS, Lewis LL, et al. Control of geohelminths by delivery of targeted chemotherapy through schools. Trans R Soc Trop Med Hyg 1990;84:115-20.

44. Amhara region on Disaster Prevention and Preparedness Commission (DPPC). Strengthening Emergency response Abilities/SERA Project; 2000

45. Moges Lewetegn. Prevalence of Intestinal Parasites among Preschool Children and Maternal Knowledge, Attitude and Practice on Prevention and Control of Intestinal Parasites in Senbete and Bete Towns, North Shoa, Ehiopia. Addis Ababa University master thesis, 2015.

46. Sady H, Al-Mekhlafi HM, Atroosh WM, et al. Knowledge, attitude, and practices towards schistosomiasis among rural population in Yemen. Parasites \& vectors. 2015; 8 (1):1.

47. Alemayehu B, Tomass Z. Schistosoma mansoni infection prevalence and associated risk factors among schoolchildren in Demba Girara, Damot Woide District of Wolaita Zone, Southern Ethiopia. Asian Pacific journal of tropical medicine. 2015; 8(6):457-63. https://doi.org/10.1016/j.apjtm.2015.05.009 PMID: 26194830

48. Gebreyohanns A, Legese $\mathrm{MH}$, Wolde $\mathrm{M}$, et al. Prevalence of intestinal parasites versus knowledge, attitude and practices with special emphasis to Schistosoma mansoni among individuals who have river water contact in Addiremets town, Western Tigray, Ethiopia. PLoS ONE 2018. 13(9): e0204259.https://doi.org/10.1371/journal.pone.0204259

49. Liza A. Nyantekyi, Mengistu Legesse.et al. Intestinal parasitic infections among under-five children and maternal awareness about the infections in Shesha Kekele, Wondo Genet, Southern Ethiopia, Ethiopian Journal of Health Development · July 2011

50. M Bhattacharya, V Joon, $V$ Jaiswal. Water handling and sanitation practices in rural community of Madhya Pradesh: A knowledge, attitude and practice study. Indian J Prev Soc Med 2011; 42(1):9497. 
51. Guidelines for the evaluation of soil-transmitted helminthiasis and schistosomiasis at community level, WHO/CTD/SIP/98.1 WHO, Geneva; 1998.

52. Sayasone, Somphou, Mak, Tippi K, Vanmany, Monely et al. Helminth and intestinal protozoa infections, multiparasitism and risk factors in Champasack province, Lao People's Democratic Republic. PLoS neglected tropical diseases. 2011. V 5, issue 4

53. Midzi et al. Knowledge attitudes and practices of grade three primary school children in relation to schistosomiasis, soil transmitted helminthiasis and malaria in Zimbabwe. BMC Infectious Diseases 2011, 11:169 http://www.biomedcentral.com/1471-2334/11/169)

\section{Figures}

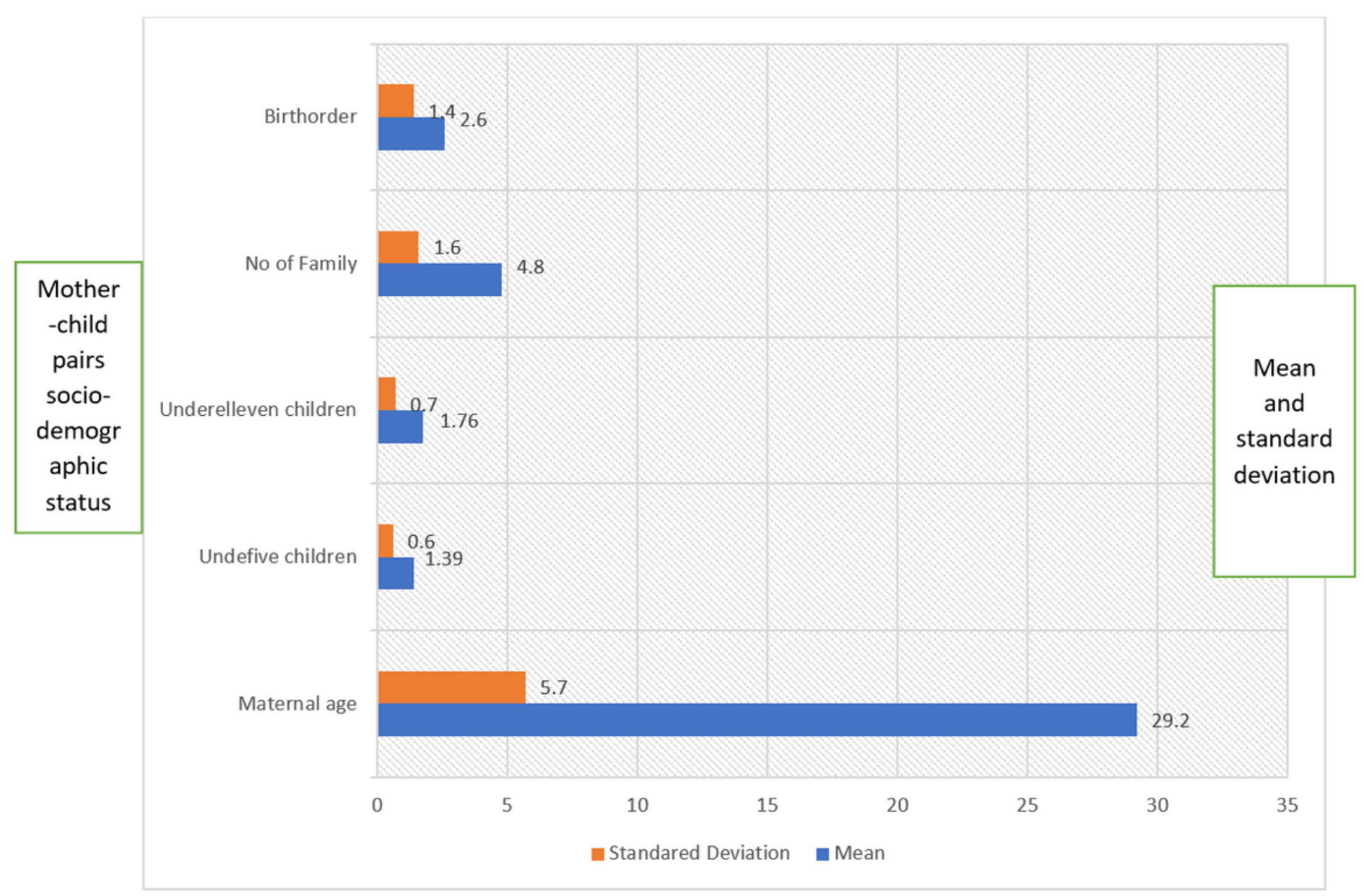

\section{Figure 1}

The mean and standard deviation of maternal age, number of family, birth order, and number of children from the householdsincluded to the study in Sekota town, Waghimra zone, Ethiopia, 2018/19 


\section{Supplementary Files}

This is a list of supplementary files associated with this preprint. Click to download.

- Quesionary12.docx 